\title{
APLIKASI CLIENT-SERVER UNTUK SISTEM INFORMASI KEPUSTAKAAN PADA PERPUSTAKAAN PEGADILAN NEGERI SIDIKALANG
}

\author{
Ronald Fernando Hutasoit ${ }^{1}$, Boy Kardo Panjaitan ${ }^{2}$ Marlince Novita Karoseri Nababan ${ }^{3}$ \\ ${ }_{1,2,3}$ Fakultas Teknologi dan Ilmu Komputer, Universitas Prima Indonesia \\ email: ronaldhutasoit58222@gmail.com, marlincenovitakaroserinababan@unprimdn.ac.id
}

\begin{abstract}
This study aims to solve the problem of processing book data at the Sidikalang District Court Library, which currently does not have an information system to process library data such as book data, library member data, borrowing and returning books. In the absence of information regarding available books, the library leader, namely customer representative recreation, the Sidikalang District Court does not know exactly the type and number of books available so that it can hamper the development of the library. This problem is resolved by designing a client-server application for library information systems in libraries. Sidikalang District Court. With this library information system it is hoped that it can simplify the work of librarians, the system for recording book data and member data becomes more structured, fast and accurate, accelerates the process of searching for member data, book data, borrowing, and returning transaction data, and services to library members become more good.
\end{abstract}

Keywords: Client Server, Sistem, Library.

\section{PENDAHULUAN}

Teknologi komputerisasi dalam dunia berkembang saat ini dapat dimanfaatkan untuk mengerjakan banyak hal [1]-[4], [5]-[14]. Oleh sebab itu, menjadi pilihan yang harus digunakan untuk membantu pengolahan data yang banyak, sehingga menghasilkan informasi yang berguna dan berkualitas [15]-[21]. Aplikasi client-server untuk sistem informasi kepustakaan merupakan salah satu bentuk pemanfaatan komputer untuk menghasilkan sebuah sistem informasi kepustakaan yang dapat mengelola data dan informasi yang dibutuhkan dengan lebih baik [22].

Perpustakaan Pengadilan Negeri Sidikalang saat ini belum mempunyai sebuah sistem informasi yang baik untuk melakukan pengolahan data-data perpustakaan seperti data buku, data anggota perpustakaan, data peminjaman dan pengembalian buku. Dengan tidak adanya informasi mengenai buku yang tersedia, pimpinan perpustakaan yaitu customer representative recreation Pengadilan Negeri Sidikalang tidak mengetahui secara pasti jenis dan jumlah buku yang tersedia sehingga dapat menghambat terhadap perkembangan perpustakaan.

Kepustakaan ini, dapat memberikan informasi-informasi yang dibutuhkan oleh customer representative recreation Pengadilan Negeri Sidikalang dalam pengambilan keputusan untuk perkembangan perpustakaan dan pihak perpustakaan Pengadilan Negeri Sidikalang dapat memberikan pelayanan terbaik kepada anggotanya yaitu dengan tersedianya kemudahan-kemudahan dalam melakukan proses pencarian buku yang ingin dibaca atau dipinjam serta kemudahan dalam proses peminjaman dan pengembalian buku yang dapat dilakukan dalam waktu yang relatif lebih singkat.

Adapun tujuan dari penelitian ini adalah penerapan ilmu yang telah diperoleh saat kuliah di Universitas Prima Indonesia "UNPRI" dengan membangun sebuah aplikasi client-server untuk sistem informasi kepustakaan pada perpustakaan Pengadilan Negeri Sidikalang.

\section{METODE PENELITIAN}

Adapun permasalahan yaitu: tidak adanya informasi mengenai buku yang tersedia sehingga anggota perpustakaan memerlukan waktu yang cukup lama untuk mendapatkan buku yang diinginkannya, proses peminjaman buku oleh anggota perpustakaan tidak efektif karena petugas perpustakaan harus melakukan pencatatan terhadap keanggotaan dan buku yang akan dipinjam yang memungkinkan terjadinya kesalahan yang akan berakibat buruk di 
kemudian hari, proses pengembalian buku yang telah dipinjam cukup sulit dilakukan karena petugas perpustakaan harus mencari kartu peminjaman anggota dalam arsip-arsip peminjaman lainnya sehingga membutuhkan waktu yang relatif lama, dan tidak adanya informasi mengenai buku yang tersedia, baik yang sedang dipinjam ataupun yang tidak sedang dipinjam serta informasi denda akibat keterlambatan pengembalian buku bagi pimpinan perpustakaan sehingga menghambat terhadap pengambilan keputusan oleh pimpinan perpustakaan [23].

Agar permasalahan menjadi lebih terarah dan sistematis sesuai dengan sasaran yang ingin dicapai, maka penelitian ini dibatasi pada masalah yang akan dibahas, yaitu Analisis yang dilakukan hanya terbatas pada pengolahan datadata kepustakaan seperti data buku yang tersedia, data anggota perpustakaan, data peminjaman dan pengembalian buku oleh anggota perpustakaan, dan aplikasi client-server yang akan dibangun terbatas hanya pada penggunaan Local Area Network (LAN) di dalam gedung perpustakaan.

Dalam penelitian ini maka pengumpulan data dilakukan dengan 3 cara:

1. Penelitan Lapangan (Field Research)

Dalam hal ini penulis melakukan penelitian langsung ke lapangan untuk mengumpulkan data secara langsung dengan cara menyajikan pertanyaan-pertanyaan dan mengumpulkan formulir yang ada.

2. Penelitian Kepustakaan (Library Research) Pengumpulan data juga dilakukan dengan membaca buku-buku literatur, diktat kuliah, buku-buku yang berkaitan dengan penelitian ini, kliping majalah, dan artikel-artikel yang berasal dari internet.

Sebuah perpustakaan pada prinsipnya mempunyai tiga kegiatan pokok, yaitu pertama mengumpulkan (to collect) semua informasi yang sesuai dengan bidang kegiatan dan misi lembaganya dan masyarakat yang dilayaninya. Kedua, melestarikan, memelihara, dan merawat seluruh koleksi perpustakaan agar tetap dalam keadaan baik, utuh, layak pakai, dan tidak mudah rusak, baik karena pemakaian maupun karena usianya (to preserve) [6]. Ketiga, adalah menyediakan untuk siap dipergunakan dan diberdayakan (to make available) atas seluruh sumber informasi dan koleksi yang dimiliki perpustakaan, bagi para pemakainya. Kata "perpustakaan" berasal dari kata pustaka, yang berarti (1) kitab, buku-buku, (2) kitab primbon. Kemudian kata pustaka mendapat awalan per dan akhiran an, menjadi perpustakaan. Perpustakaan mengandung arti: (1) kumpulan buku-buku bacaan, (2) bibliotek, dan (3) buku-buku kesusastraan.

\section{HASIL DAN PEMBAHASAN}

\subsubsection{Data Flow Diagram}

Data Flow Diagram (DFD) Sistem Informasi Perpustakaan pada Pengadilan Negeri Sidikalang, untuk sistem yang penulis rancang sebagai berikut:

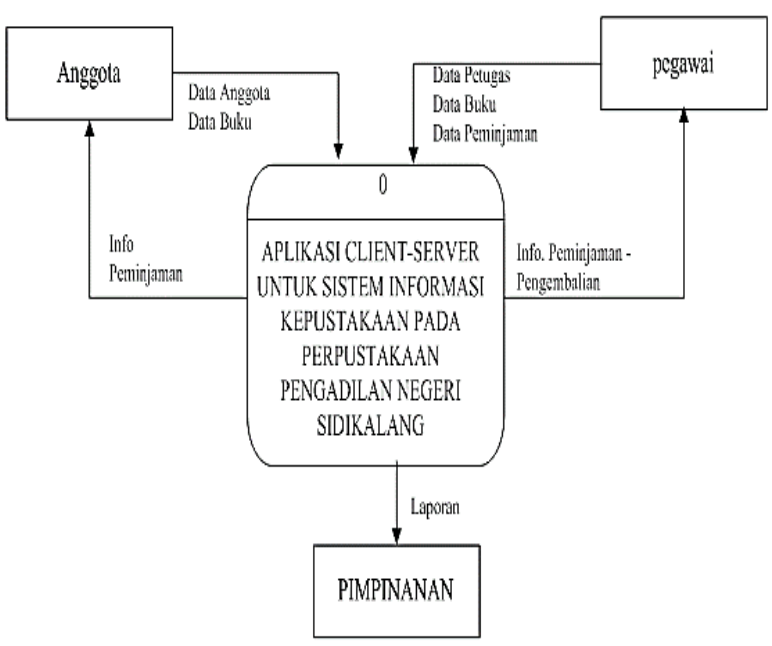

Gambar 1. Diagram Konteks

\subsubsection{Basis Data (Database)}

Adapaun basis data yang akan digunakan dalam perancangan aplikasi client-server untuk sistem informasi kepustakaan pada perpustakaan Pegadilan Negeri Sidikalang ini terdiri dari tabel Anggota, tabel buku, tabel peminjaman dan tabel detil peminjaman.

Tabel 1. Peminjaman

\begin{tabular}{|c|c|c|l|}
\hline $\begin{array}{c}\text { Field } \\
\text { Name }\end{array}$ & Type & Size & \multicolumn{1}{|c|}{ Description } \\
\hline KdPnjm & Text & 5 & $\begin{array}{l}\text { Kode } \\
\text { Peminjaman }\end{array}$ \\
\hline KdBku & Text & 5 & Kode Buku \\
\hline
\end{tabular}


Tabel 2. Anggota

\begin{tabular}{|l|c|c|l|}
\hline $\begin{array}{c}\text { Field } \\
\text { Name }\end{array}$ & Type & Size & Description \\
\hline NoAgta & Text & 5 & $\begin{array}{l}\text { Nomor } \\
\text { anggota }\end{array}$ \\
\hline TglDaft & Date/Time & - & $\begin{array}{l}\text { Tanggal } \\
\text { Daftar }\end{array}$ \\
\hline NmaAgta & Text & 25 & $\begin{array}{l}\text { Nama } \\
\text { Anggota }\end{array}$ \\
\hline Jk & Text & 6 & $\begin{array}{l}\text { Jenis } \\
\text { Kelamin }\end{array}$ \\
\hline Almt & Text & 35 & $\begin{array}{l}\text { Alamat } \\
\text { anggota }\end{array}$ \\
\hline Kls & Text & 25 & Kelas \\
\hline
\end{tabular}

Tabel 3. Buku

\begin{tabular}{|l|c|c|l|}
\hline $\begin{array}{c}\text { Field } \\
\text { Name }\end{array}$ & Type & Size & Description \\
\hline KdBku & Text & 5 & Kode buku \\
\hline JdlBku & Text & 35 & Judul Buku \\
\hline JnsBku & Text & 25 & Jenis Buku \\
\hline Peng & Text & 25 & $\begin{array}{l}\text { Pengarang } \\
\text { buku }\end{array}$ \\
\hline Pnrbt & Text & 20 & $\begin{array}{l}\text { Penerbit } \\
\text { buku }\end{array}$ \\
\hline ThnTrbt & Text & 4 & $\begin{array}{l}\text { Tahun Terbit } \\
\text { buku }\end{array}$ \\
\hline Kota & Text & 15 & Kota \\
\hline Jlh & Number & Integer & Jumlah buku \\
\hline
\end{tabular}

Tabel 4. Detil Peminjaman

\begin{tabular}{|c|c|c|l|}
\hline $\begin{array}{c}\text { Field } \\
\text { Name }\end{array}$ & Type & Size & Description \\
\hline KdPnjm & Text & 5 & $\begin{array}{l}\text { Kode } \\
\text { Peminjaman }\end{array}$ \\
\hline TglPnjm & Date/Time & - & $\begin{array}{l}\text { Tanggal } \\
\text { Peminjaman }\end{array}$ \\
\hline KdPtgs & Text & 5 & $\begin{array}{l}\text { Kode } \\
\text { Petugas }\end{array}$ \\
\hline NoAgta & Text & 5 & No anggota \\
\hline
\end{tabular}

\subsection{Hasil}

Berikut hasil dari program Aplikasi Client-Server Untuk Sistem Informasi Kepustakaan Pada Perpustakaan Pengadilan Negeri Sidikalang.

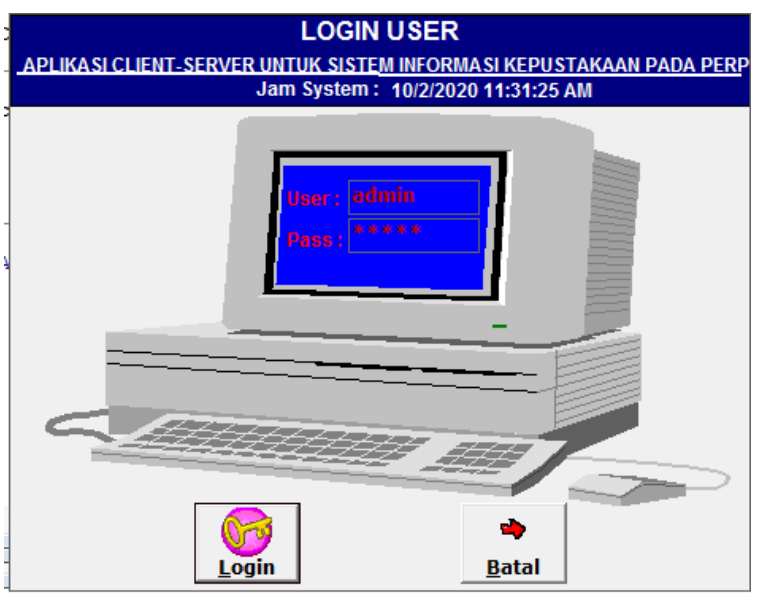

Gambar 3.1 Desain Menu Login

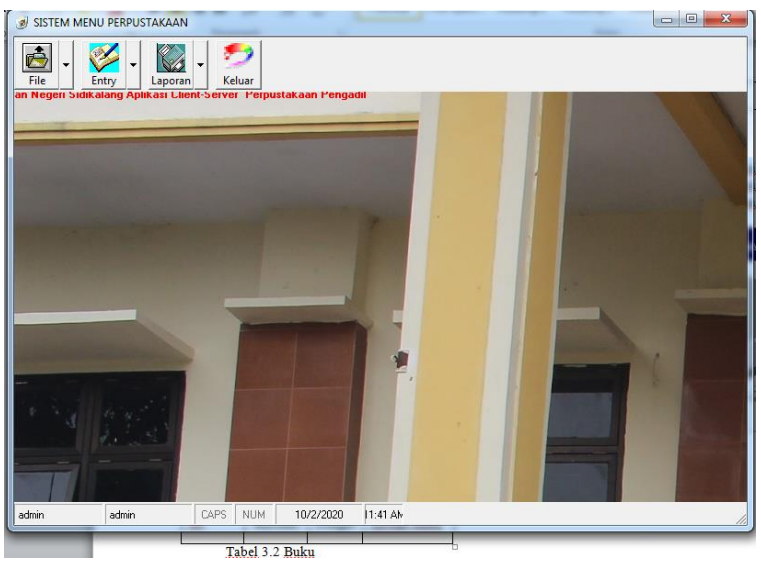

Gambar 3.2 Desain Menu Utama

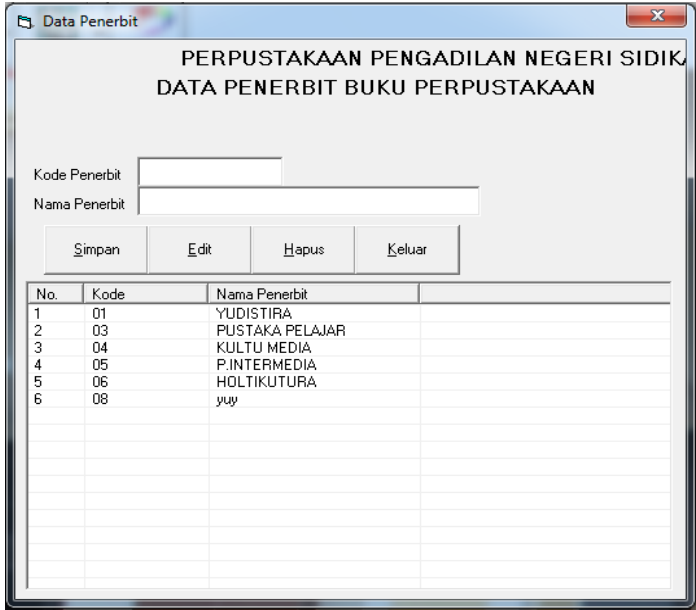

Gambar 3.3 Desain Menu Penerbit 


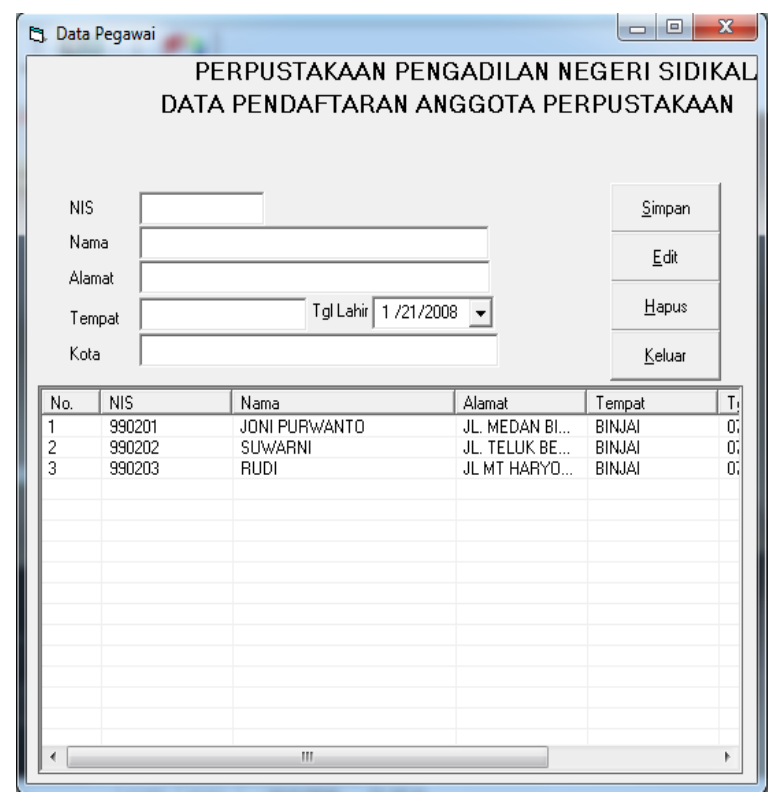

Gambar 3.4 Desain Menu Pegawai

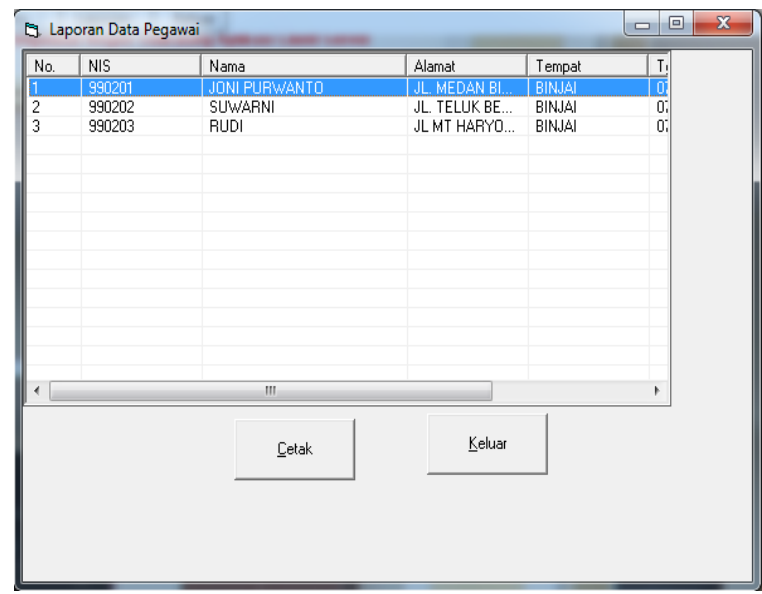

Gambar 3.5 Desain Lap Data Pegawai

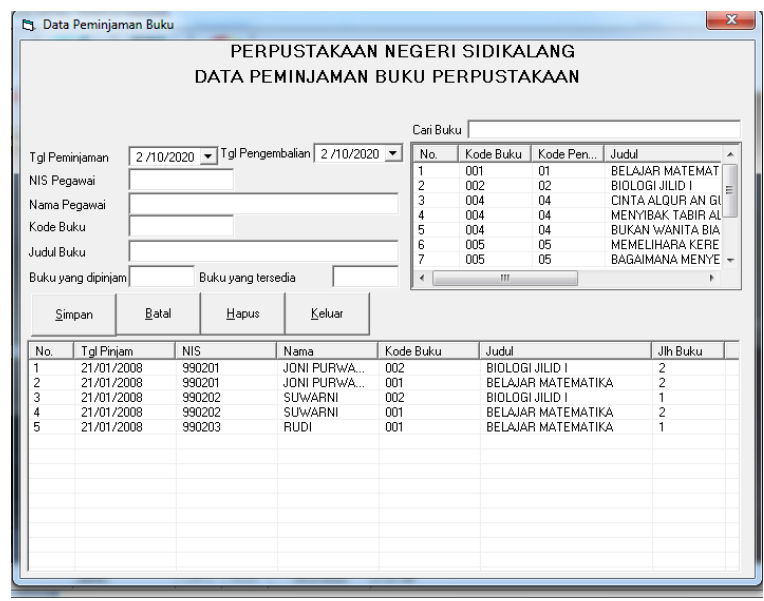

Gambar 3.6 Desain Data Pinjaman Buku

\section{KESIMPULAN}

Kesimpulan yang dapat diambil dari pembuatan aplikasi client-server untuk sistem informasi kepustakaan pada perpustakaan pengadilan negeri sidikalang adalah:

1. Telah dapat dibangun sistem perpustakaan yang berguna untuk mengelola data buku diperpustakaan di kantor Pengadilan Negeri Sidikalang yang telah bisa dioperasikan pada Perpustakaan tersebut.

2. Dengan adanya sistem Informasi perpustakaan ini, maka di harapkan dapat mempermudah kerja petugas perpustakaan, sistem pencatatan data buku dan data anggota menjadi lebih terstruktur, cepat dan akurat, mempercepat proses pencarian data anggota, data buku, data transaksi peminjaman maupun pengembalian, serta pelayanan terhadap anggota perpustakaan menjadi lebih baik, sehingga diharapkan permasalahan pengelolaan data yang ada dapat ditanggulangi dengan baik.

\section{REFERENSI}

[1] P. D. P. Adi and A. Kitagawa, "Quality of Service and power consumption optimization on the IEEE 802.15.4 pulse sensor node based on Internet of Things," Int. J. Adv. Comput. Sci. Appl., 2019.

[2] P. D. P. Adi and A. Kitagawa, "Performance evaluation of E32 long range radio frequency $915 \mathrm{MHz}$ based on internet of things and micro sensors data," Int. J. Adv. Comput. Sci. Appl., vol. 10, no. 11, pp. 38-49, 2019.

[3] P. D. P. Adi and A. Kitagawa, "ZigBee Radio Frequency (RF) performance on Raspberry Pi 3 for Internet of Things (IoT) based blood pressure sensors monitoring," Int. J. Adv. Comput. Sci. Appl., 2019.

[4] M. Niswar et al., "Performance evaluation of ZigBee-based wireless sensor network for monitoring patients' pulse status," in Proceedings - 2013 International Conference on Information Technology and Electrical Engineering: "Intelligent 
and Green Technologies for Sustainable Development”, ICITEE 2013, 2013.

[5] W. Purba, S. Aisyah, and S. P. Tamba, "Perancangan Sistem Pakar Diagnosa Penyakit Mata Katarak Menggunakan Konsep Metode Runut Mundur," JUSIKOM PRIMA (Junal Sist. Inf. Ilmu Komput. Prima), vol. 1, no. 1, 2017.

[6] G. J. Yanris, “Analisis Dan Implementasi Data Mining Dalam Menganalisa Kendala Akademik Yang Sering Dikeluhkan Mahasiswa AMIK Labuhanbatu (Studi Kasus: Amik Labuhanbatu)," Informatika, vol. 4, no. 1, pp. 15-24, 2016.

[7] J. Simatupang and S. Sianturi, "PERANCANGAN SISTEM INFORMASI PEMESANAN TIKET BUS PADA PO. HANDOYO BERBASIS ONLINE," J. Intra Tech, vol. 3, no. 2, pp. 11-25, 2019.

[8] V. Sihombing and G. J. Yanris, "PENERAPAN APLIKASI DALAM MENGOLAH ASET DESA (STUDI KASUS: KEPENGHULUAN SRI KAYANGAN)," J. Mantik Penusa, vol. 4, no. 1, pp. 12-15, 2020.

[9] V. Sihombing, "Aplikasi Simade (Sistem Informasi Manajemen Desa) Dalam Meningkatkan Pelayanan Administrasi di Kepenghuluan Bakti Makmur Kecamatan Bagan Sinembah Kab. Rokan Hilir Riau," SISTEMASI, vol. 7, no. September, pp. 292-297, 2018.

[10] J. Simatupang, "Perancangan Sistem Inventori Barang pada Toko Nichos Jaya Menggunakan Metode FIFO," J. Intra Tech, vol. 1, no. 1, pp. 31-42, 2017.

[11] V. Sihombing, "Sistem Informasi Penjualan Mobil Suzuki Di Dealer Bagan Batu," SISTEMASI, vol. 7, no. 2, pp. 113119, 2018.

[12] W. Purba, S. Tamba, and J. Saragih, "The effect of mining data k-means clustering toward students profile model drop out potential," J. Phys. Conf. Ser., vol. 1007, no. 1, p. 12049, 2018.

[13] A. Ardian, I. Purnama, and V. Sihombing, "Perancangan Aplikasi Pengolah Data Siswa Berbasis Android (Studi Kasus: Mis Nurul Huda Labuhan Batu Selatan),' Pengabdi. Masy. Ika Bina En Pabolo, vol. 1, no. 1, pp. 40-53, 2019.

[14] Fricles Ariwisanto Sianturi, "Analisa metode teorema bayes dalam mendiagnosa keguguran pada ibu hamil berdasarkan jenis makanan," Tek. Inf. dan Komput., vol. 2, no. 1, pp. 87-92, 2019.

[15] H. A. Simbolon and V. M. M. Siregar, "Perancangan Sistem Informasi Berbasis E-Commerce Untuk Peningkatan Penjualan Produk Jersey Olah Raga," $J$. Tek. Inf. dan Komput., vol. 1, no. 2, pp. 49-54, 2018.

[16] V. M. Siregar and H. Sugara, "Perancangan Dan Implementasi Aplikasi Penggajian Berbasis Dekstop Pada Murni Sadar English Course," J. Tek. Inf. dan Komput., vol. 1, no. 2, pp. 42-48, 2018.

[17] V. M. M. Siregar, H. Sugara, and I. M. Siregar, "Perancangan Sistem Informasi Pendataan Barang Pada PT. Serdang Hulu," J. Comput. Bisnis, vol. 12, no. 2, pp. 111-117, 2018.

[18] V. M. M. Siregar, H. Sugara, and G. A. Purba, "Aplikasi Pencatatan Laporan Penjualan Kita-Kita.Net Berbasis Web," TEKINKOM, vol. 2, no. 1, pp. 80-86, 2019.

[19] S. S. S, A. T. Purba, and V. M. M. Siregar, "Sistem Pendukung Keputusan Kelayakan Pemberian Pinjaman Kredit Menggunakan Metode Topsis Pada Cum Caritas HHKBP Pematangsiantar," J. Tek. Inf. dan Komput., vol. 3, no. 1, p. 1, Sep. 2020.

[20] A. T. Purba and V. M. M. Siregar, "Sistem Penyeleksi Mahasiswa Baru Berbasis Web Menggunakan Metode Weighted Product," TEKINKOM, vol. 3, no. 1, pp. 1-8, 2020. 
[21] H. Sugara, E. Sirait, M. A. Hanafiah, and N. F. Siagian, "Sistem Informasi Pembayaran SPP Pada SMK Swasta Teladan Tanah Jawa Menggunakan Vb.Net," J. Tek. Inf. dan Komput., vol. 3, no. 1, p. 14, 2020.

[22] B. S. D. Oetomo, "Konsep Dan Aplikasi Server Dan System Terdistribusi," Yogyakarta Andi, 2006.

[23] H. A. Riyanto, Sadikin, and M. R. Zanuddin, "Sistem Informasi Perpustakaan Umum Grati Kabupaten Pasuruan Berbasis Web Menggunakan Program Php Dan Database Mysql," J I M $P$ - J. Inform. Merdeka Pasuruan, vol. 1, no. 2, pp. 1-14, 2016. 